\title{
A contribuição dos laudos periciais do assistente social na elaboração das sentenças de processos judiciais do Benefício de Prestação Continuada/Idoso
}

The contribution of social worker forensic reports in the determination of court-case sentences involving the elderly continued support Social Security Benefit

(BPC/Idoso)

La contribuición de los laudos periciales del asistente social en la elaboración de las sentencias de procesos judiciales del Beneficio de Prestación Continua

Lisete Maria Pozatti Sergio Antonio Carlos

RESUMO: Fundamentando-se na legislação e no trabalho dos assistentes sociais peritos judiciais, estudaram-se os laudos e as sentenças de 79 processos de idosos requerentes do Benefício de Prestação Continuada (BPC), junto ao Tribunal Regional Federal da $4^{\mathrm{a}}$ Região (TRF4-RS), com sentenças proferidas em 2017. A análise do conteúdo foi realizada com o auxílio do software NVivo12. Identificou-se uma variedade de concepções empregadas na construção do documento pericial e uma efetiva contribuição dos laudos sociais nas sentenças. Palavras-chave: Idoso; BPC; Laudo pericial. 
ABSTRACT: Court-case sentences and reports from 79 cases with elderly plantiffs were studied based on the legislation and the work of social workers specialized in forensic reports. All sentences were ruled in 2017, involving the elderly continued support Social Security Benefit (BPC/Idoso) in the Federal Regional Court of the 4th Region (TRF4-RS). The content analysis was performed using NVivol2 software. It was identified a variety of conceptions used in forensic reports construction and an effective contribution to the court-case sentencing process was observed.

Keywords: Elderly; BPC; Forensic report.

RESUMEN: Se fundamental en la legislación y en el trabajo de los asistentes sociales peritos judiciales. Se estudarion los lados y sentencias de 79 processos de ancianos solicitantes del Beneficio de Prestación Continua (BPC junto al Tribunal Regional Federal de la 4ta. Región (TRF-4 - RS) con sentencias concedidas en 2017. El análisis de contenido fue realizado con auvilio de software NVivo12. Se identificó una variedad de concepciones empleadas en la construcción del documento pericial y un efectiva contribuición de los laudos sociales en las sentencias.

Palabras clave: Anciano; BPC; Laudo Pericial.

\section{Introdução}

Este artigo se baseia em alguns aspectos da dissertação sobre a judicialização do Benefício de Prestação Continuada (BPC) de pessoas idosas, produzida pela primeira autora, sob a orientação do segundo. Fundamenta-se na legislação e no trabalho dos assistentes sociais como peritos judiciais. Foram estudados processos da Subseção de Porto Alegre, do Tribunal Regional Federal da $4^{\mathrm{a}}$ Região - Rio Grande do Sul (TRF4-RS), Brasil, que tiveram sentenças proferidas no ano de 2017. O objetivo é compreender a contribuição do laudo pericial dos assistentes sociais nas sentenças de solicitação judicial do benefício.

A escolha do tema tem relação com caminhos e experiências percorridos pela primeira autora. Há momentos, nos diversos percursos e propósitos, em que se encontram curvas, surpresas e entroncamento; o questionamento sobre a prática realizada é um deles.

Pozatti, L. M., \& Carlos, S. A. (2019). A contribuição dos laudos periciais do assistente social na elaboração das sentenças de processos judiciais do Benefício de Prestação Continuada/Idoso. Revista Kairós-Gerontologia, 22(3), 255-275. ISSNprint 1516-2567. ISSNe 2176-901X. São Paulo (SP), Brasil: FACHS/NEPE/PEPGG/PUC-SP 
Na caminhada pessoal e profissional, um tema se faz presente e chama a atenção: a comunicação. O que ocorre no momento da escuta, como a voz, palavras, sons, ênfases, silêncios, podem ser interpretados e/ou traduzidos, considerando-se a responsabilidade daquele registro, o propósito de visibilidade e encaminhamentos devidos. A comunicação é um fator relevante quando o trabalho está centrado na realização de perícias - que, no geral, ocorrem em ocasião única de encontro do profissional com a pessoa que está em situação de requerente de tal atividade.

Traçar o caminho do mestrado, após experiência acumulada como assistente social e perita, é um desafio. Transitar entre perícias, judicialização, laudos, e sentenças é outro desafio. Assim, identificar os elementos que compõem os laudos elaborados pelos assistentes sociais, presentes nas sentenças proferidas nos processos de judicialização do BPC/idoso, é o caminho escolhido seguindo o propósito.

Cada perícia é única, sendo um desafio e uma oportunidade no exercício das competências do profissional. Cada situação é um aprendizado, uma reflexão sobre o que tem a ver, ou o que é afetado na interação entre os envolvidos, como que entoando: "E eu com isso?", “O que diz respeito às minhas questões?”. Destaca-se que há possibilidade constante da presença do inusitado, em cada realidade, e a reflexão do que representa o papel do perito, especificamente em perícia social.

A experiência de mais de uma década na atividade de perita assistente social e o acúmulo em número de perícias ultrapassou, em muito, o primeiro milhar. Locais e situações diversas se tornaram elementos de construção e de estímulo, para abordar a riqueza vivenciada e analisada por diferentes faces e olhares.

Todavia, sempre esteve presente a questão de compreender a função do laudo social na trajetória de judicialização do BPC. Tendo em vista a definição do objeto de estudo, foi sendo traçado o caminho e delimitado o foco, referenciando a questão: qual a contribuição do laudo do assistente social, na sentença sobre judicialização do BPC/idoso?

\section{Para pavimentar a redução das desigualdades}

As políticas sociais brasileiras revelam faces da história em que podem ser vislumbrados avanços, retrocessos e embates em todas as etapas: concepção; construção; 
organização; regulamentação; e, por fim, sua materialização e efetivação. O envolvimento de diferentes segmentos sociais e a correlação de forças, em seus argumentos, compõem a riqueza da sua elaboração. Com a dinâmica da realidade em que a elaboração é aplicada, dos ajustes e das pressões de enfrentamento às situações da realidade da população, buscam-se políticas que possibilitem alterações fundamentais. Passa-se por enfrentamentos e embates de interesses antagônicos que perfazem as mudanças, sobretudo das políticas sociais, com repercussão econômica ou de abrangência para a conquista de direitos humanos.

A Constituição Federal de 1988 (Brasil, 1988) é um marco na história brasileira em relação a uma nova política pública de direitos - dentre eles, o da Assistência Social. A Assistência Social é direito do cidadão e dever do Estado. O BPC é um benefício previsto na Lei n. ${ }^{\circ}$ 8.742/93 (Lei Orgânica da Assistência Social - LOAS), que, em seus artigos $1^{\circ}$ e $2^{\circ}$, regulamentam os artigos 203 e 204 da Constituição Federal de 1988 (CF-88), versando sobre sua organização. A Constituição Federal assegura ao cidadão pleno direito à seguridade social, que forma o tripé: Previdência Social, Saúde e Assistência Social. A Assistência Social, como uma política social, traz o reconhecimento de direitos, referidos no $\operatorname{artigo} 1^{\circ}$ da LOAS “[...] a assistência, direito do cidadão e dever do Estado, é Política de Seguridade Social não contributiva, que provê os mínimos sociais, realizada através de um conjunto integrado de ações de iniciativa pública e da sociedade, para garantir o atendimento às necessidades básicas [...]” (Brasil, 1993: art. 1º).

\section{A judicialização do Benefício de Prestação Continuada}

$\mathrm{O}$ BPC é um benefício não contributivo, vinculado à Assistência Social, custeado com recursos do Fundo Nacional de Assistência Social (FNAS). Destina-se a atender tanto Pessoas com Deficiência (PCD), quanto idosos sem condições de manutenção própria ou por familiares. Consiste na transferência mensal de um salário-mínimo ao beneficiário (Brasil, 1993). Destina-se a brasileiros natos ou naturalizados e a estrangeiros legalmente residentes no país, que atendam aos critérios de elegibilidade. No caso de idosos, os critérios de elegibilidade, previstos na LOAS (Brasil, 1993), além da idade de 65 anos, é que a renda familiar mensal per capita seja inferior a um quarto do salário mínimo. 
Com o advento do Estatuto do Idoso, Lei n. ${ }^{\circ}$ 10.471/03 (Brasil, 2003), no parágrafo único do artigo 34, o valor recebido pelo primeiro idoso beneficiário do BPC não é considerado para cálculo da renda familiar, no caso de solicitação de um segundo BPC.

A judicialização, além de ser uma forma de acesso a um direito da população, demonstra que os profissionais, em diversas instâncias, quando engajados em soluções não somente da situação apresentada, posicionam-se com empatia aos cidadãos menos favorecidos social e economicamente. Revela-se, assim, a característica do Poder Judiciário no meio sociopolítico e na ação para a redução de desigualdades e para a garantia de direitos. Ante a complexidade do tema, considera-se que este possa ser um momento rico de discussão sobre dados apresentados pela pesquisa e seu detalhamento, em conjunto com servidores do Poder Judiciário, peritos e demais interessados. A qualificação profissional sobre tema da judicialização e Serviço Social é primordial para os peritos sociais.

\section{Miserabilidade: parâmetros e critérios}

A LOAS, no artigo 20, $\S 3^{\circ}$, refere que, para concessão do BPC, é necessária a comprovação da condição de vulnerabilidade e miserabilidade. Além da renda per capita inferior a $1 / 4$ do salário mínimo (s.m.) vigente, podem ser utilizados outros meios comprobatórios, conforme o $\S 11^{\circ}$ :

$\S$ 11. "Para concessão do benefício de que trata o caput deste artigo, poderão ser utilizados outros elementos probatórios da condição de miserabilidade do grupo familiar e da situação de vulnerabilidade, conforme regulamento (Incluído pela Lei n. ${ }^{\circ}$ 13.146, de 2015) (Vigência)".

O termo miserabilidade, abordado na Lei n. ${ }^{\circ} 8.742 / 93$, causa acaloradas discussões entre os segmentos que se aproximam do assunto. Entretanto, há uma aparente concordância quando se afirma que o conteúdo do parágrafo $3^{\circ}$, do artigo 20 , está defasado. 
Salienta-se que, completando 25 anos da promulgação da LOAS, a realidade econômica brasileira viveu transformações políticas, sociais e jurídicas, que delinearam propostas para modificação dos critérios para a concessão de benefícios abrangendo toda a área da Assistência Social. Encontram-se argumentos e reflexões nos diversos segmentos que consideram ser necessário revisar, demonstrando que o tema é atual nos diferentes espaços em que transita.

O critério da necessidade ou miserabilidade se refere à hipossuficiência econômica ${ }^{1}$, conforme a Lei n. ${ }^{\circ} 8.742 / 93$, parágrafo $3^{\circ}$ do artigo 20. Assim regulamentada, a família cuja renda mensal per capita seja inferior a $1 \frac{1}{4}$ do salário mínimo é considerada incapaz de prover a manutenção da pessoa com deficiência ou idoso.

$\mathrm{O}$ teor do requisito miserabilidade explicita divergências de argumentos entre o Instituto Nacional de Seguridade Social e o Poder Judiciário, identificadas também entre os posicionamentos dos magistrados e dos profissionais que atuam na Política de Assistência. Em artigo apresentado por Silva (2014), encontra-se referência de que o Supremo Tribunal Federal, que julgou a constitucionalidade do critério definido no art. $20, \S 3^{\circ}$ da LOAS, em conjunto com os Tribunais Regionais Federais, passou a adotar outra definição de miserabilidade, de meio salário mínimo, conforme diversos programas sociais instituídos pelo governo federal. A controvérsia em relação ao padrão de miserabilidade, para a obtenção do BPC, se situa sobre a possibilidade ou não da flexibilização dos requisitos contidos na LOAS.

O Benefício de Prestação Continuada, por ser um direito social, e o único programa de combate à pobreza, tem condições de ser requerido junto ao Poder Judiciário, ante a negativa de acesso no âmbito do Poder Executivo.

Os estudos sobre judicialização acessados evidenciam dois posicionamentos. Um deles destaca o caráter não coletivo da ação judicial, aumentando a desigualdade entre os que poderiam receber o benefício. Outro destaque é que os conteúdos dos documentos e trâmites do processo judicial ampliam a informação relativa ao direito.

\footnotetext{
${ }^{1}$ Hipossuficiência: termo usado no meio jurídico para se referir à parte que é considerada mais frágil ou carente financeiramente em uma relação processual. Para fins de comprovação, é possível apresentar em Juízo uma declaração de hipossuficiência econômica, popularmente conhecida como "declaração de pobreza". A partir dessa declaração, o Juiz pode determinar que as custas de um processo sejam gratuitas (justiça gratuita).
} 


\section{A elaboração de laudos socioeconômicos}

Tanto Fávero (2003) quanto Mioto (2001), ao discutirem os instrumentos utilizados em demandas judiciais, apresentam pontos em comum. Discutem as demandas de realização e do exame por parte do profissional, para abordar o tema fazendo uso de instrumental para emitir um parecer técnico.

A instrumentalidade do Serviço Social é variada e contempla diferentes objetivos e formas de abordagem de situações que requisitam o olhar do profissional. Os instrumentos contribuem para a análise do desenvolvimento da profissão e posicionamento ante a realidade. As diversas áreas de ação do profissional estabelecem e acrescentam peculiaridades aos documentos utilizados, como o laudo social e o parecer social.

\section{Laudo Social}

O laudo está previsto no Código de Ética do Serviço Social como "elemento de prova no intuito de subsidiar a decisão no processo judicial”. Na Lei de Regulamentação da Profissão (Brasil, 2012, p. 45), no Art. 5º estão entre as atribuições privativas do Assistente Social: “[...] realizar vistorias, perícias técnicas, laudos periciais, informações e pareceres sobre a matéria de Serviço Social".

Fávero (2009) traz uma definição detalhada e técnica, oportunizando o direcionamento e a compreensão sobre itens importantes na constituição do corpo do instrumento. Afirma que o laudo é o registro que documenta as informações significativas, recolhidas por meio do estudo social, permeado ou finalizado com interpretação e análise. Em sua parte final, via de regra, registra-se o parecer conclusivo, do ponto de vista do Serviço Social. Conclusivo, no sentido de esclarecer que, naquele momento. com base no estudo científico realizado, chegou-se à determinada conclusão (Fávero, 2009, p. 28). A autora aponta: a demanda judicial para a realização do laudo; as informações sobre as pessoas envolvidas; a metodologia utilizada; os instrumentos e alguns conceitos que possam elucidar o tema; e o fechamento do documento em forma de parecer. 


\section{Parecer Social}

O parecer social tem, em sua maioria, a função de síntese conclusiva, e é colocado ao final do documento elaborado por profissional da área. Fávero (2009) - uma das autorasreferência sobre a temática - aponta três momentos de expressão do posicionamento profissional. A primeira se dá quando é solicitado parecer que apresente análise sucinta do objeto em questão, indicando alternativas e conclusões, de forma sintética. Uma segunda oportunidade é a conclusão de um laudo que pode ser determinado judicialmente, tendo por base as informações processuais e/ou complementares. A terceira pode ser com base na análise de dois profissionais da área, que abordam a questão, ou elaborada por um assistente técnico, referenciando o laudo emitido por outro profissional.

\section{Estratégias e procedimentos metodológicos}

Trata-se de uma pesquisa qualitativa descritiva documental, em que as análises incidem preponderantemente sobre os laudos socioeconômicos e as sentenças judiciais.

O corpus utilizado na pesquisa é composto por processos judiciais de solicitação do BPC/idoso, na Subseção de Porto Alegre, TRF4-RS, com sentenças de primeira instância, proferidas em 2017. Foram incluídos os processos que não estavam sob o segredo de justiça, com laudo socioeconômico e com chaves de acesso fornecidas pelo TRF4-RS até outubro/2018. Atenderam os requisitos e foram analisados 79 processos.

Foi realizada uma análise de conteúdo com base em Bardin (1988), utilizando-se as seguintes etapas:

- leitura flutuante separadamente dos laudos e sentenças, com o objetivo de identificar conteúdos emergentes em cada modalidade, na busca por elementos para a criação de categorias;

- registro, em planilhas, de dados demográficos e caracterização da população solicitante de BPC/idoso;

- análise do conteúdo das planilhas, dos laudos e das sentenças com o software de apoio à análise de dados qualitativos NVIVO 12. 
A opção pelo NVivo 12 se deu porque ele é adequado à pesquisa qualitativa com alto número de dados e fontes diversas. O NVivo possui um sistema de indexação do material disposto, que é construído pelo pesquisador: "nós", que armazenam “categorias", definindo as informações que as compõem. Com base no conteúdo, possuem codificação que se relacionam aos "nós" e "fontes", favorecendo a busca e mantendo a informação localizada nos documentos originais. "Classificações", "atributos", "casos", entre outros, são termos usuais na aplicação do Nvivo 12, buscando fazer conexão das fontes originais.

Cabe salientar que diversos autores (Coruja, 2018; Jacks, et al., 2016; Lage, 2011) concordam e ressaltam que nenhuma das ferramentas ocupa o lugar e o trabalho do pesquisador. O programa não decide, não interpreta, nem analisa os dados, o que é de responsabilidade do pesquisador, porém possibilita uma análise mais complexa, ampliandose as possibilidades da pesquisa, executando apenas o que é solicitado por ele. De acordo com o posicionamento dos autores, encontra-se a complementação de que a utilidade se dá em caso de a pesquisa possuir planejamento e boa fundamentação, uma vez que a classificação dos dados é organizada "a partir do problema de pesquisa e da base teórica do trabalho" (Coruja, 2018, p. 192).

Dos diversos recursos disponibilizados pelo NVivo, nesta pesquisa, foi utilizada, basicamente, a contagem de palavras. A partir desse recurso, foi possível identificar as palavras mais utilizadas, tanto pelos assistentes sociais, nos laudos, quanto pelos juízes, nas sentenças. De posse dos resultados, optou-se por apresentá-los tanto em forma descritiva quanto gráfica (árvore de palavras), para dar destaque ao material presente nos processos.

As considerações finais do artigo são apresentadas a partir de um infográfico que exemplifica o percurso da solicitação do BPC.

Para estudar os laudos e sentenças constantes dos processos judiciais, que tiveram a sentença de primeira instância proferida no ano de 2017, junto ao TRF4-RS, foram seguidos os seguintes trâmites: a) autorização do TRF4-RS para utilização dos processos; b) aprovação do Comitê de Ética do Instituto de Psicologia (UFRGS), número 2.762.730/2018. Em função de questões éticas com relação à pesquisa, optou-se pela não utilização de uma experiência autoetnográfica da primeira autora, mas, sim, por uma abordagem a partir dos documentos produzidos com a participação de vários peritos.

Pozatti, L. M., \& Carlos, S. A. (2019). A contribuição dos laudos periciais do assistente social na elaboração das sentenças de processos judiciais do Benefício de Prestação Continuada/Idoso. Revista Kairós-Gerontologia, 22(3), 255-275. ISSNprint 1516-2567. ISSNe 2176-901X. São Paulo (SP), Brasil: FACHS/NEPE/PEPGG/PUC-SP 


\section{Encontrados no percurso}

À medida que a pesquisa era construída, alguns termos saltavam aos olhos, seja pela frequência em que apareciam nos laudos e/ou sentenças, ou pelos contextos em que eram utilizados. Os conteúdos apresentados nos laudos periciais, mesmo com a indicação de quesitos idênticos por parte do juiz, cresciam nas diferenciações em relação às abordagens e aos detalhamentos, mostrando ser um aspecto de importância para a pesquisa. A reflexão, que acompanhava a leitura dos laudos, era de igual forma sobre a formação, a sua estrutura, o conteúdo e a aplicabilidade junto à sentença.

A fotografia é um elemento usual nos processos judiciais, não só como quesito, mas também como instrumento dos laudos e das citações nas sentenças. A não utilização das fotografias se deve ao fato de que, no momento da submissão do projeto de pesquisa ao Comitê de Ética, não estava previsto o uso.

\section{a) Dos requerentes}

A maioria dos requerentes se encontra na faixa etária de 65 a 69 anos $(88,61 \%)$, o que indica que são pessoas que recentemente atingiram a idade mínima para solicitar o benefício. As mulheres representam 56,96\% dos autores dos processos estudados, enquanto 43,04\%, são homens. No aspecto da ocupação, há diversos relatos de início de atividade laborativa em tenra idade, não contribuição previdenciária sua e/ou por parte do empregador e baixa escolaridade.

Quanto à residência, da totalidade, 27,65\% estão localizadas em Porto Alegre (RS), 13,43\% em Alvorada, 8,69\% em Viamão, e 5,53\% em Guaíba. Em relação às condições de posse da habitação, $37,13 \%$ são proprietários, $1,85 \%$ moram em casas cedidas, e 6,32\% em casas alugadas.

Em relação à situação familiar, identificou-se um grande número com mais de um filho, a maioria deles vivendo só ou com companheiro/a. 


\section{b) Da moradia}

O tema habitação tomou maior relevância no transcorrer da análise do material. Não somente como item pertinente aos quesitos apresentados, mas porque está presente nos quesitos propostos pelos juízes e em todos os laudos dos peritos, de diferentes maneiras, critérios e olhares sobre o local de residência do requerente. $\mathrm{O}$ termo moradia tem maior vulto quando consideradas variações da palavra, presente em todos os processos: residência, habitação, domicílio ou casa.

\section{c) Dos laudos periciais}

Laudo pericial é o documento em que o técnico, ou especialista, refere suas observações e seu parecer, quando designado para realizar avaliação de uma situação determinada de sua área profissional. Utilizado para compor os processos judiciais, como meio de prova, não limita os magistrados unicamente a seu conteúdo. Critérios como imparcialidade e clareza compõem o laudo, sendo considerado importante o posicionamento profissional de quem o elaborou.

Constata-se a diversidade na forma de elaboração de laudos periciais. Nas conclusões sobre a concessão do BPC/idoso, 53,16\% dos laudos são favoráveis, e 5,06\% não favoráveis. Chama a atenção que 25,31\% dos laudos não trazem explícitos parecer nem análise, e 16,45\% apresentam parecer sem análise, ou apresentam análise sem parecer. Os dados levam a reflexões: sobre a construção do laudo; sobre os parâmetros utilizados; sobre a formação profissional, o conhecimento sobre instrumento/instrumentalidade; e sobre posicionamento profissional. Eles evidenciam a necessidade de capacitação continuada.

\section{d) Das sentenças}

Em todas as sentenças, há referência à LOAS e ao Estatuto do Idoso (art. 34 da Lei 10.741/2003). A compreensão dos critérios para concessão do BPC é questionada por parte dos magistrados, considerando a realidade vivida pelo requerente. 
Entre os questionamentos mais presentes está o parâmetro da renda e a despesa, os agravos de saúde e a habitação e os critérios de miserabilidade. Jurisprudências foram referidas em 34 sentenças. Demonstram as reflexões, os posicionamentos e a determinação por parte de alguns magistrados na interpretação dos critérios de miserabilidade, quando da análise de concessão do BPC/idosos. A flexibilização para a renda per capita de até 1/2 salário mínimo é referenciada em 21 sentenças.

As sentenças demonstram divergências de entendimentos, no sentido de flexibilização do critério objetivo da renda. Compreende-se que pode haver avaliação sem limitação financeira estipulada (inferior a 1/4 s.m.), não excluindo outros elementos de prova, que informem sobre condição socioeconômica do requerente e sua família - valendo-se, para apuração, o que é elencado nos laudos socioeconômicos. Demonstrada a possibilidade de ocorrer divergência conceitual sobre situação real do requerente do BPC, pode-se ter esclarecimento a partir de elementos socioeconômicos referidos no laudo pericial.

\section{e) Da vulnerabilidade e miserabilidade}

O termo vulnerabilidade pode ser identificado em diferentes contextos - muitas vezes, o assistente social utiliza "vulnerabilidade social", qualificando o primeiro termo, sem especificações. Alguns contextos citados denotam a que se referem e poucos são os processos que indicam se tratar de uma ou mais características (econômica, gênero, violência, dependência de terceiros, risco de saúde, habitação, miserabilidade, drogas, acesso, habitação, outros). O termo, por sua vez, é encontrado 25 vezes nos pareceres e/ou análises nos laudos dos assistentes sociais. Vulnerabilidade, referindo-se à base legal, é citada em 53\% das sentenças seguida pela associação com miserabilidade não comprovada (32 casos) e associada à habitação (22 casos). Miserabilidade é referida em todas as 79 sentenças e uma única vez em laudo pericial.

Os laudos e sentenças possuem uma riqueza de conteúdo e discurso, permeada por significados. Exemplifica-se, abaixo, um dos recursos utilizados na análise de resultados: árvore de significados, de palavra ou de associação. As figuras 1 e 2 possibilitam a visualização do contexto aplicado, mantendo fidelidade aos trechos que antecedem (esquerda) e procedem (direita) no exemplo de "miserabilidade". Na árvore abaixo, destacam-se alguns 
termos, que se tornam evidentes pela repetição nos processos. Por exemplo, o termo vulnerabilidade (Fig.1) é utilizado pelos juízes, nas sentenças, para expressarem o que entendem como uma situação de "miserabilidade". Ou seja, apesar de os textos dos processos não indicarem uma diferença semântica, são utilizados pelos mesmos como correlatos.

Fig. 1 - Árvore de palavras a partir do termo "miserabilidade" com destaque para a "vulnerabilidade"

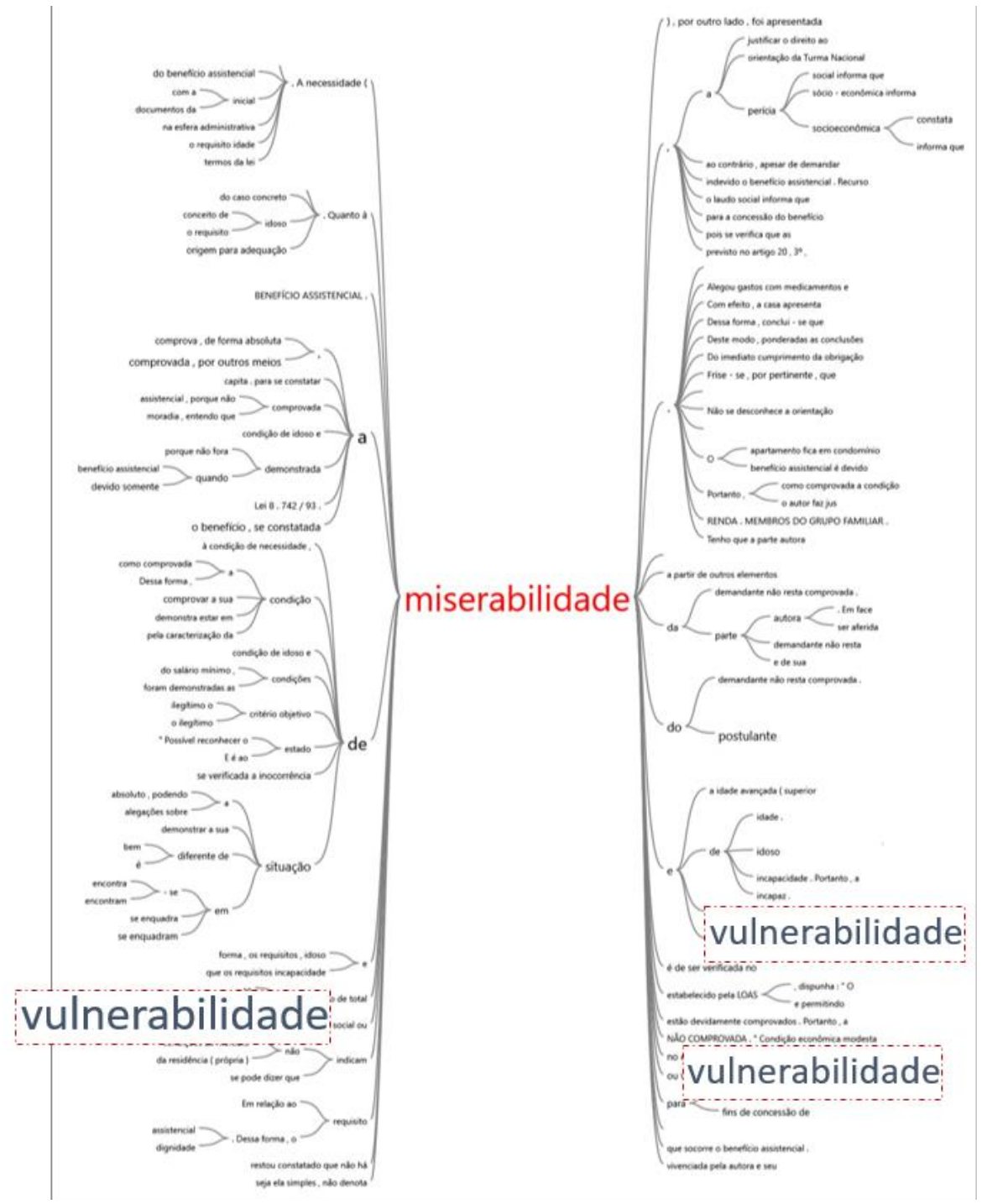

Fonte: NVivo12 a partir de processos judiciais pesquisados junto ao TRF-4 
$\mathrm{Na}$ árvore acima, observa-se a relação da comprovação da miserabilidade com o deferimento, ou não, do recurso impetrado. Quando o juiz considera que a miserabilidade foi comprovada, há o deferimento; quando não, o recurso é indeferido.

Usando-se a mesma árvore de palavras, podem-se destacar outras relações que aparecem a partir das sentenças. Além da repetição do termo "vulnerabilidade", para justificar o que os juízes entendem por miserabilidade, a relação de termos que se relacionam a renda e moradia (Fig. 2, abaixo) também são destacados pelos juízes nas sentenças, mostrando critérios importantes para a comprovação da "miserabilidade" (mesmo que, isoladamente, isso nem sempre se confirme).

Fig.2 - Árvore de palavras a partir do termo "miserabilidade" com destaque para a relação com renda e moradia

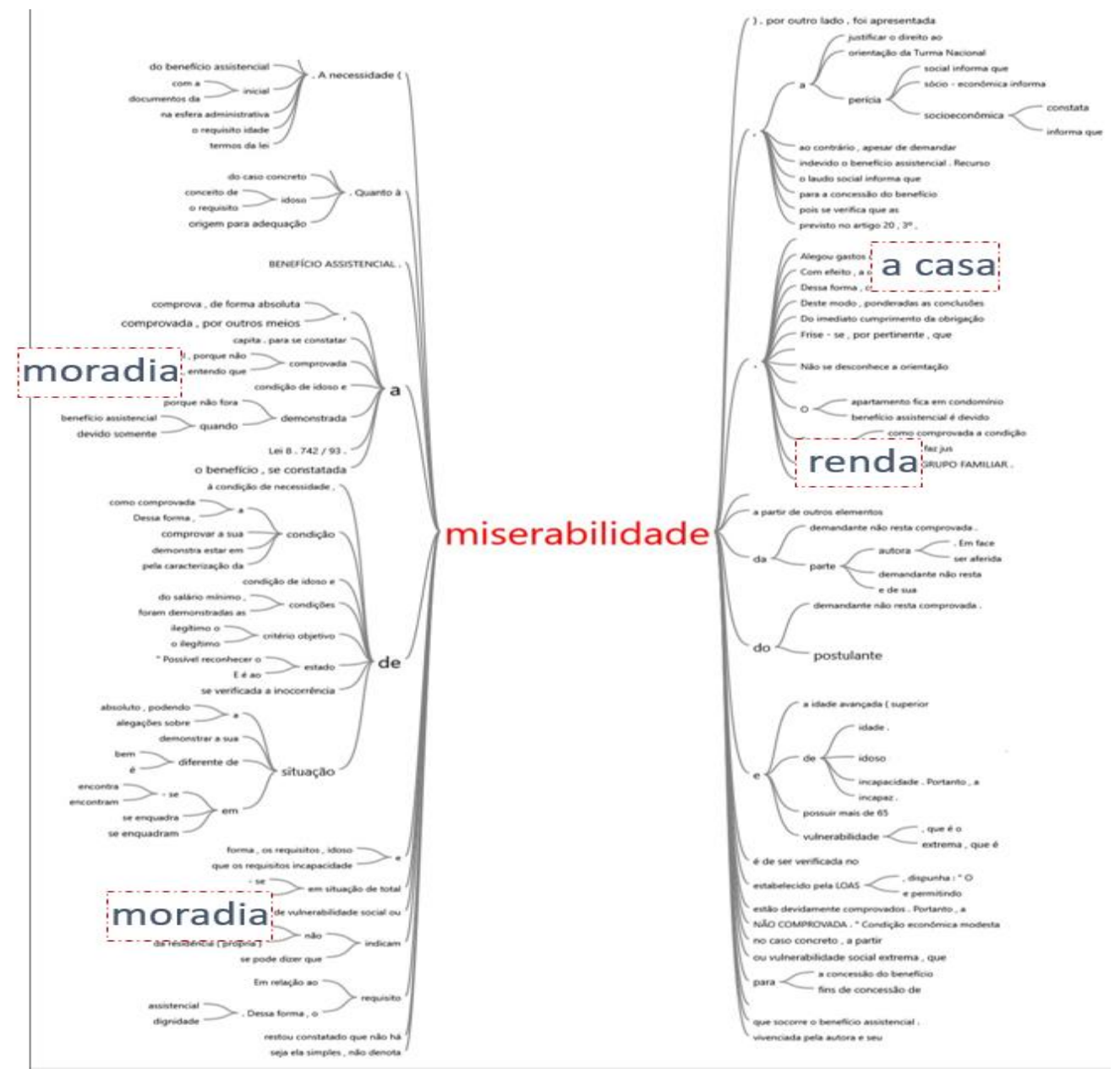

Fonte: NVivo12 a partir de processos judiciais pesquisados junto ao TRF-4 
Como é possível, pelas associações presentes na árvore de significados, que vulnerabilidade aparece constantemente associada à miserabilidade. De acordo com a análise dos textos, a vulnerabilidade é uma situação, ou uma realidade, normalmente associada às questões, econômica e social. No lado direito da árvore, é possível verificar como a vulnerabilidade é configurada: alimentação e moradias precárias, valores informados e relatos. Pela árvore, também é possível constatar que situação de vulnerabilidade, uma das formulações mais correntes, é expressa ou demonstrada.

Quando a miserabilidade é acionada como conceito, em geral, aparece nas sentenças amparada por citações da lei. Em geral, aparece como demonstrada, comprovada, uma situação capaz de ser reconhecida. Da mesma forma, aparece associada ao conceito de vulnerabilidade social, que ainda é adjetivada como extrema em algumas situações. Quando aparece, é justificada com a citação da questão da idade dos idosos. A moradia também é acionada nas estruturas em que o termo aparece textualmente, sendo usado como critério para comprovação de uma situação de miserabilidade ou não.

A realidade de cada um dos solicitantes é de suma importância, mas sem perder o intuito de caracterizá-la como um conjunto da população e agrupá-la, colocando-os na posição de demandantes das políticas sociais. Feito isso, o profissional consegue traduzir os dados verificados in loco e conduzir as informações para o documento, o laudo social.

A presença ou a ausência da condição de miserabilidade é essencial para a decisão do juiz em conceder ou não o benefício. Em todas as sentenças de concessão do BPC analisadas, consta que a miserabilidade está comprovada independentemente do valor per capita ser inferior ou superior ao parâmetro de 1/4 S.m. A condição de moradia foi identificada como fundamental para a comprovação de miserabilidade. A análise da mesma é feita pelo perito por meio do detalhamento escrito e por fotografias acostadas no laudo.

A análise dos laudos e das sentenças, com a utilização de árvores de palavras, levou a questionar se seria possível representar, por meio de uma fórmula a relação dos critérios objetivos e subjetivos: renda e miserabilidade. Foi construída uma fórmula, representada no quadro abaixo, que foi denominado de Quadro Grego. Todos os casos foram classificados, analisados e distribuídos de acordo com critérios e subdivisões de renda e submetidos aos componentes da fórmula.

Pozatti, L. M., \& Carlos, S. A. (2019). A contribuição dos laudos periciais do assistente social na elaboração das sentenças de processos judiciais do Benefício de Prestação Continuada/Idoso. Revista Kairós-Gerontologia, 22(3), 255-275. ISSNprint 1516-2567. ISSNe 2176-901X. São Paulo (SP), Brasil: FACHS/NEPE/PEPGG/PUC-SP 
Quadro 1 - Quadro Grego: Fórmula de renda e miserabilidade

\begin{tabular}{|l|l|}
\hline$+\mathrm{R} \tilde{\mathrm{n}} \mathrm{M}=\tilde{\mathrm{n}} \mathrm{BPC}$ & $+\mathrm{R} \mathrm{M}=\mathrm{BPC}$ \\
\hline$-\mathrm{R} \tilde{\mathrm{n}} \mathrm{M}=\tilde{\mathrm{n}} \mathrm{BPC}$ & $-\mathrm{R} \mathrm{M}=\mathrm{BPC}$ \\
\hline
\end{tabular}

Assim, onde se lê: $+\mathrm{R}=$ Renda superior a $1 \frac{1}{4}$ de salário mínimo (s.m.), $-\mathrm{R}=$ renda Inferior a 1/4 S.m., $\tilde{\mathrm{n}} \mathrm{M}=$ Miserabilidade, não comprovada, $\mathrm{M}=$ Miserabilidade Comprovada, $\tilde{\mathrm{n}} \mathrm{BPC}-\mathrm{BPC}$ não concedido, $\mathrm{BPC}=\mathrm{BPC}$ concedido.

Quadro 2 - aplicação da fórmula à totalidade dos casos estudados

\begin{tabular}{|c|c|c|c|c|c|c|c|c|c|c|}
\hline \multirow{3}{*}{$\begin{array}{l}\text { RENDA PER } \\
\text { CAPITA }\end{array}$} & \multicolumn{4}{|c|}{ MISERABILIDADE } & \multicolumn{4}{|c|}{ DECISÃO } & \multirow{2}{*}{\multicolumn{2}{|c|}{ TOTAL }} \\
\hline & \multicolumn{2}{|c|}{ Comprovada } & \multicolumn{2}{|c|}{ Não Comprovada } & \multicolumn{2}{|c|}{ BPC concedido } & \multicolumn{2}{|c|}{ BPC não concedido } & & \\
\hline & $\mathbf{N}$ & $\%$ & $\mathbf{N}$ & $\%$ & $\mathbf{N}$ & $\%$ & $\mathbf{N}$ & $\%$ & $\mathbf{N}$ & $\%$ \\
\hline Sem renda & 18 & 22,77 & 09 & 11,40 & 18 & 22.77 & 09 & 11,39 & 27 & 34.18 \\
\hline - de $1 / 4$ S.m. & 12 & 15,18 & 07 & 8,87 & 12 & 15.18 & 07 & 8,87 & 19 & 24.05 \\
\hline $1 / 4$ S.m & 07 & 8,87 & 26 & 32,91 & $\mathbf{0 7}$ & 8.87 & 26 & 32,91 & 33 & 41.77 \\
\hline TOTAL & 37 & 46.82 & 42 & 53,18 & 37 & 46.82 & 42 & 53.18 & 79 & 100 \\
\hline
\end{tabular}

Fonte: Processos judiciais pesquisados junto ao TRF-4 com sentenças proferidas em 2017

Com a totalidade das sentenças analisadas, os resultados com decisão de improcedente (ou seja, BPC não concedido) são de 53,18 \%, enquanto os de procedentes (BPC concedido) são de $46.82 \%$. Essas informações nos levam a pensar sobre o argumento de subjetividade, tanto do assistente social como do juiz, na contribuição para escolha e ampliação dos parâmetros estabelecidos para análise da situação.

A renda per capita referida (sem renda, menos de 1/4 S.m., igual ou acima de 1/4 S.m.) tem valor definido após a possível redução do que foi considerado plausível (desconto para idoso, PCD, despesas e Programa Bolsa Família). Possui variações, pois se observou que, mesmo com renda superior a 1/4 S.m., após o desconto, alguns casos são contemplados com parâmetro de miserabilidade comprovada. Assim, fica evidente que a renda não é o único elemento para considerar o idoso em situação de miserabilidade. Também, são avaliados o contexto e as condições de habitação. Destaque entre miserabilidade e decisão: todos os casos em que a miserabilidade foi considerada comprovada foram contemplados com o resultado da sentença como procedente à concessão do BPC, ao passo que os que tiveram miserabilidade não comprovadas foram considerados como improcedentes ao pleiteado. 


\section{Considerações Finais}

Considera-se que o infográfico representa a síntese para a compreensão do trajeto da judicialização dos processos analisados. Também, destaca-se a aplicação, na totalidade dos casos, da fórmula desenvolvida, apresentando resultados congruentes. Para melhor compreensão, descreve-se, a seguir, cada um dos elementos identificados por seu respectivo número constante na figura abaixo (Fig.3).

Figura 3 - Infográfico que sintetiza o processo de judicialização do BPC e a concessão do benefício

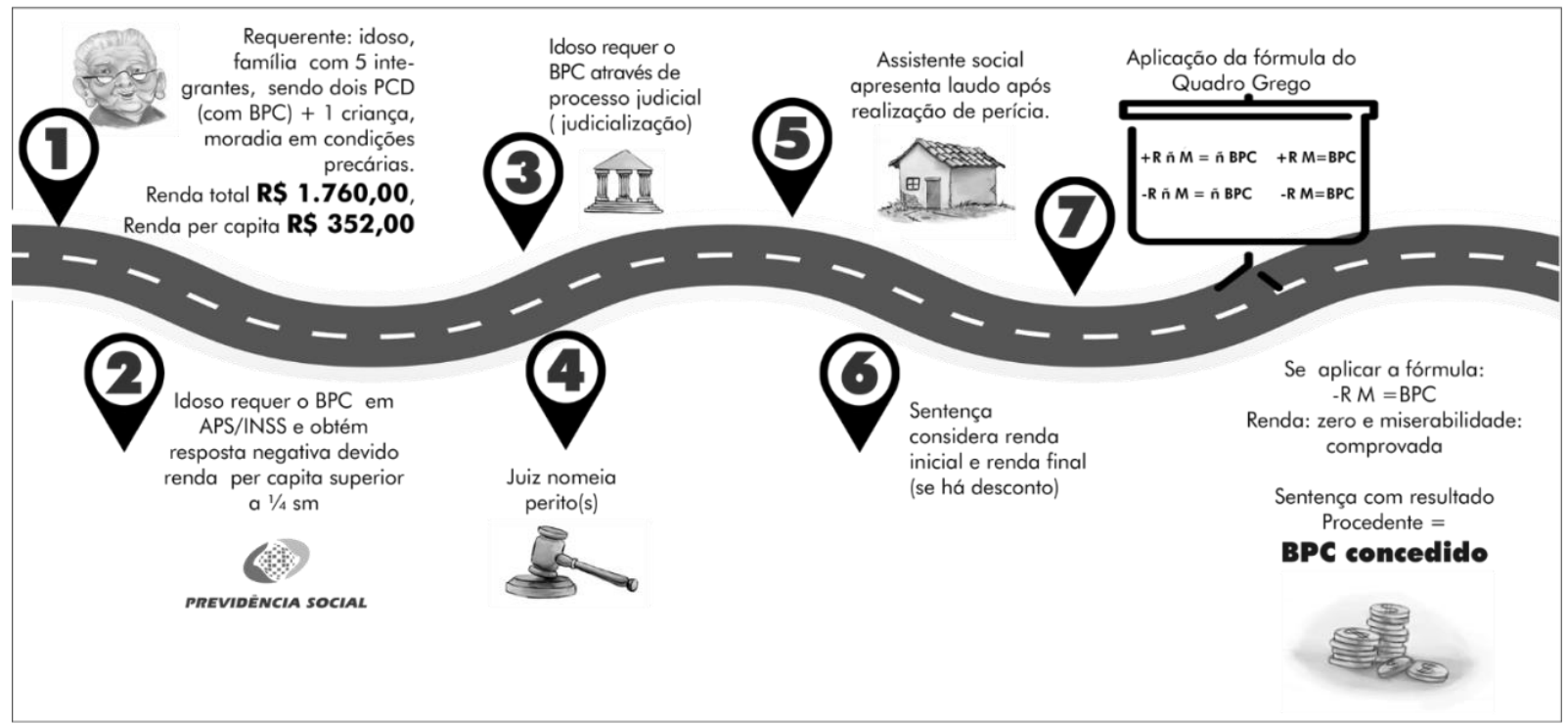

Fonte: conteúdo da autora, com infográfico de Paula Coruja e ilustrações de Vinícius Dullius

O infográfico traz a ação integral, desde a fase inicial de requerimento do BPC pelas pessoas idosas, incluindo o processo de judicialização. Representa uma síntese de todo o trabalho investigativo que é descrito a seguir, apresentando o que se pode considerar como um dos casos típicos:

1 - Requerente: Pessoa idosa, tendo seu grupo familiar composto por cinco integrantes, sendo dois deles Pessoas com Deficiência e usuários de BPC, além de uma criança. A moradia é precária e a renda bruta familiar e per capitas definidos. 
2 - Pessoa idosa requer o BPC, em uma agência da Previdência Social (APS/INSS), apresentando a documentação solicitada. Sendo afirmativa a resposta, ela passa a receber o BPC e não segue os próximos passos.

Caso a resposta seja negativa, justificada por a renda per capita estar acima dos critérios estabelecidos - ou seja, superior a 1/4 salário mínimo -, pode seguir para a próxima etapa.

3 - O representante legal (advogado/a ou defensor público) ingressa com pedido de benefício, por meio de processo judicial, o que caracteriza a judicialização. Os recursos advocatícios podem ser públicos ou privados, a critério e disponibilidade do solicitante.

4 - No transcorrer do processo, o juiz nomeia um profissional assistente social para realização de perícia. A nomeação vem acompanhada de quesitos e definição de prazos.

5 - O/a assistente social nomeado/a realiza a visita domiciliar e/ou institucional, para realizar perícia socioeconômica, emitindo, posteriormente, o laudo pericial.

6 - Tendo por base as informações processuais diversas, ocorre a sentença sobre solicitação de concessão de benefício. A sentença apresenta argumentos baseados em legislação, que fundamentam a decisão de ser procedente ou improcedente. Nos casos analisados, observamse critérios objetivos e subjetivos, sendo identificados: renda bruta; origem; possíveis descontos; despesas; condições da realidade vivenciada pela família; entre outros.

7 - No exemplo apresentado no infográfico, o magistrado considerou que a renda era oriunda de dois BPCs. Portanto, com o valor a ser descontado, o resultado passa a ser igual a zero. Outro aspecto relevante na sentença e, também, caracterizado na fórmula é que, além da renda, há o critério de miserabilidade comprovada ou não.

A pesquisa realizada revela informações preciosas sobre a conexão de critérios, significados e sujeitos envolvidos no processo de judicialização. A relação ocorre entre: a) as pessoas idosas que requerem o benefício assistencial, ingressando via judicial como garantia de direito; b) o profissional de Serviço Social que realiza perícia no domicílio do solicitante; e c) o juiz que aprecia os dados dos idosos e suas famílias, considerando os registros nos laudos sociais e a legislação a respeito.

Em diversos casos pesquisados, verifica-se que o juiz, mesmo com critérios apoiados na legislação, busca, nos dados apresentados no laudo, algum fator que possa caracterizar o direito à concessão. Ou, ante o apresentado, considera que não condiz com o benefício e argumenta, muitas vezes, ampliando o entendimento e levando a jurisprudências e acórdãos.

Pozatti, L. M., \& Carlos, S. A. (2019). A contribuição dos laudos periciais do assistente social na elaboração das sentenças de processos judiciais do Benefício de Prestação Continuada/Idoso. Revista Kairós-Gerontologia, 22(3), 255-275. ISSNprint 1516-2567. ISSNe 2176-901X. São Paulo (SP), Brasil: FACHS/NEPE/PEPGG/PUC-SP 
Os profissionais, as organizações e o poder público, quando se omitem ou recuam em seu papel de proteção social, contribuem na criação, reprodução ou perpetuação de situações de desigualdade ao acesso às políticas e aos serviços. Também, não contribuem à tomada de consciência sobre condições de vida das populações em situações de vulnerabilidades e precarizações.

A efetiva contribuição do laudo social na sentença amplia e visibiliza as condições de vida dos idosos requerentes e das suas famílias. Há diversidade nos registros e não existem parâmetros por parte dos assistentes sociais. Mesmo tendo como critério a contemplação de quesitos apresentados, sejam pelo juiz, pelo INSS ou pela parte autora, na maioria das vezes, os peritos limitam-se a responder a eles. Partindo do princípio de que todos os profissionais possuem formação acadêmica básica e, por tratar-se de um documento usual aos assistentes sociais peritos, para analisar a situação exposta, orientada pelos mesmos quesitos, surpreende que haja tanta diferenciação na confecção dos laudos. Torna-se fator preponderante para estudos, na questão de elaboração de eixos sobre o assunto, na formação, no entendimento da relevância do documento como expressão do profissional. Dando contribuições, assim, para a profissão ou para o campo a que se destina - no caso estudado, ao Poder Judiciário e à Assistência Social.

Ao empreender esta pesquisa, o deixar-se afetar ocorreu a cada leitura de laudo e sentença, a cada história retratada e destino decidido para conseguir compreender as características e o papel do trabalho do perito ao avaliar a situação de uma parcela da população considerada vulnerável.

Uma das constatações, não só pela pesquisa, mas pelo próprio trabalho como profissional de perícia, é de que a realidade do requerente está muito distante das sedes dos tribunais e dos computadores que escrevem os conteúdos processuais. Contudo, ousa-se comentar que a questão do distanciamento e do espaço físico chega a ser superado, e redimensionado, quando, com presença e envolvimento profissional, independentemente das dimensões concretas, é percebida a tradução e dedicação que alguns peritos e magistrados colocam para a defesa de seus argumentos com tamanha habilidade ética. Demonstrando, assim, seriedade na exposição da situação analisada, na descrição da realidade e no posicionamento do que é registrado e tornado público, não só para o requerente e sua família mas, principalmente, para que se possa continuar a contribuir com o que se acredita. 
Para a reflexão sobre a subjetividade aplicada à realidade objetiva, é mister conhecermos os critérios (objetivos e subjetivos) que levam os profissionais peritos assistentes sociais e magistrados a contribuírem para a decisão do pleito.

Considera-se o tema da pesquisa como relevante à discussão, qualificando a formação tanto acadêmica como na capacitação complementar dos interessados em áreas sociojurídicas. Da mesma forma, os resultados que foram apresentados podem ser de interesse tanto dos servidores, peritos do Poder Judiciário, quanto das organizações que trabalham com o tema da população idosa, ampliando o conhecimento e reflexões sobre questões abordadas.

\section{Referências}

Bardin, L. (1988). Análise de conteúdo. Lisboa, Portugal: Edições 70.

Brasil. (1988). Constituição da República Federativa do Brasil de 1988. Brasília, DF. Recuperado em 26 dezembro, 2017, de: http://www.planalto.gov.br/ccivil_03/constituicao/constituicaocompilado.htm.

Brasil. (1993). Lei n. ${ }^{o} 8.742$ de 7 de dezembro de 1993. Dispõe sobre a organização da Assistência Social e dá outras providências. Brasília, DF. Recuperado em 26 dezembro, 2017, de: http://www.planalto.gov.br/ccivil_03/LEIS/L8742.htm.

Brasil. (2003). Lei $n^{\circ} 10.741$ de $1^{\circ}$ de outubro de 2003. Dispõe sobre o Estatuto do Idoso e dá outras providências. Brasília, DF. Recuperado em 26 dezembro, 2018, de: http://www.planalto.gov.br/ccivil_03/leis/2003/110.741.htm.

Brasil. (2012). Código de Ética do/a Assistente Social. Lei 8.662/93 de regulamentação da profissão. (10ª ed. rev. e atual.). Brasília, DF: CFESS. Conselho Federal de Serviço Social.

Coruja, P. (2018). Comentários no youtube: uma proposta de análise a partir de uma pesquisa realizada no canal jout jout prazer. In: Morales, Y., Sousa, L., \& Lapa, B. (Orgs.). Experiências metodológicas em pesquisas da comunicação, 173-202. São Luís, MA: EDUFMA.

Fávero, E. T. (2003). O estudo social: fundamentos e particularidades de sua construção na área judiciária. In: CFESS - Conselho Federal de Serviço Social. (Org.). O estudo social em perícias, laudos e pareceres técnicos. 9-51. São Paulo, SP: Cortez.

Fávero, E. T. (2009). Instruções sociais de processos, sentenças e decisões- Serviço Social: Direitos Sociais e Competências Profissionais. In: CFESS - Conselho Federal de Serviço Social. Serviço Social - Direitos Sociais e Competências Profissionais. 1-34. São Paulo, SP: CFESS. 
Lage, M. C. (2011). Os softwares tipo CAQDAS e a sua contribuição para a pesquisa qualitativa em educação. Revista Educação Temática Digital, 12(2), 42-58. Recuperado em 01 dezembro, 2018, de: https://periodicos.sbu.unicamp.br/ojs/index.php/etd/article/view/ 1187.

Mioto, R. C. (2009). Estudos socioeconômicos. In: CFESS - Conselho Federal de Serviço Social; ABEPSS - Associação Brasileira de Ensino e Pesquisa em Serviço Social. (Orgs.). Serviço Social: direitos sociais e competências profissionais. 481-496. Brasília, DF: CFESS/ABEPSS,

Silva, D. B. e. Assistência social e o conceito de miserabilidade: uma necessária revisitação do tema. Revista Eletrônica do Curso de Direito - PUC-Minas Serro, 10, 18-34. Recuperado em 01 dezembro, 2018, de: http://periodicos.pucminas.br/index.php/DireitoSerro/article/view/8070.

Recebido em 15/07/2019

Aceito em 15/09/2019

Lisete Maria Pozatti - Assistente Social da Universidade Federal do Rio Grande do Sul (UFRGS), Mestre em Política Social e Serviço Social pelo Programa de Pós-Graduação de Política Social e Serviço Social (UFRGS).

E-mail: lisete.pozatti@ufrgs.br

Sergio Antonio Carlos - Assistente Social, Doutor em Serviço Social (PUCSP), Professor Titular aposentado. Docente colaborador convidado no Programa de Pós-Graduação de Política Social e Serviço Social, Universidade Federal do Rio Grande do Sul (UFRGS).

E-mail: sacarlos@ufrgs.br 